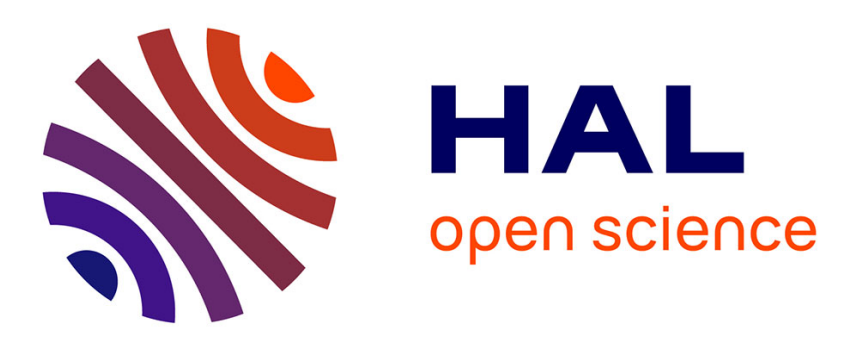

\title{
La question de la discipline dans le développement de l'Armée de terre japonaise à l'époque de Meiji (1868-1912)
}

\author{
Eric Seizelet
}

\section{To cite this version:}

Eric Seizelet. La question de la discipline dans le développement de l'Armée de terre japonaise à l'époque de Meiji (1868-1912). Histoire, économie et société, 2019, 4, pp.45-64. halshs-02493376

\section{HAL Id: halshs-02493376 \\ https://shs.hal.science/halshs-02493376}

Submitted on 27 Feb 2020

HAL is a multi-disciplinary open access archive for the deposit and dissemination of scientific research documents, whether they are published or not. The documents may come from teaching and research institutions in France or abroad, or from public or private research centers.
L'archive ouverte pluridisciplinaire HAL, est destinée au dépôt et à la diffusion de documents scientifiques de niveau recherche, publiés ou non, émanant des établissements d'enseignement et de recherche français ou étrangers, des laboratoires publics ou privés. 


\title{
La question de la discipline dans le développement de l'Armée de terre japonaise à l'époque de Meiji (1868-1912)
}

\author{
Eric SEIZELET
}

\section{Résumé}

Cet article vise à identifier la place de la discipline militaire lors de la phase de création, puis de développement d'un appareil militaire moderne dans le Japon de Meiji. Il s'appuie sur les différents instruments, politiques, administratifs, juridiques, psychologiques mis en place à cet effet par le haut commandement afin de sécuriser la « neutralité » politique des nouvelles forces armées dans cette phase délicate de transition. Il mesure l'impact des guerres contre la Chine et la Russie, au moment même où la question de la discipline militaire devient un enjeu majeur, non seulement pour légitimer le service militaire à l'intérieur, mais aussi pour consolider la position internationale du Japon en tant que nation « civilisée ».

\section{Abstract}

The purpose of this article is to identify the role played by military discipline in the wake of the creation and development of a modern military apparatus in Meiji Japan. The article deals with the multiple instruments - political, administrative, psychological set up by the military in order to secure the so-called neutrality of the new armed forces during this difficult phase of transition. It measures the impact of the war against China and Russia when military discipline became an important issue not only to legitimate the conscription system, but also to consolidate Japan's international position as a " civilized $»$ country.

La « guerre de quinze ans », entre l'incident de Mandchourie de 1931 et la défaite de 1945, a légué une image déplorable des armées impériales qui a longtemps discrédité l'institution militaire au Japon même. Complotiste, voire putschiste contre les gouvernements des partis, bras armé de l'expansionnisme et du militarisme nippons, fanatisée à l'extrême, "l'Armée de l'empereur " a laissé dans son sillage un cortège sanglant d'exactions, souvent présenté comme l'exutoire aux multiples frustrations, vexations, brimades que subissait le soldat japonais dans les cantonnements. Qu'elles aient été orchestrées, tolérées par le haut commandement, ou le résultat de dérives 
individuelles ou collectives, ces violences interrogent la question de la discipline au sein des forces armées japonaises et, au-delà, du système de valeurs dont elles sont le produit. Après la Restauration de l'autorité impériale en janvier 1868, le nouveau gouvernement s'était attelé à construire un État-nation moderne pour protéger son indépendance face à l'irruption des Puissances occidentales en Asie Orientale et y affermir sa propre position. Dans cette double perspective, le Japon entreprit de construire une armée nationale calquée sur les modèles occidentaux, d'abord français, puis allemand au milieu de années $1880^{1}$. Ce processus de construction d'une armée moderne dut faire face à de nombreuses résistances. De la part d'une partie de l'ancienne classe des guerriers que l'avènement de la conscription à partir de 1873 avait privé du monopole de l'art militaire, mais aussi de la paysannerie japonaise qui fournissait alors les gros bataillons des conscrits et pour laquelle le service militaire s'inscrivait dans la liste des " corvées », imposées non plus par le seigneur local, mais par l'Etat ${ }^{2}$. Cette force militaire fut mobilisée pour réprimer les mouvements d'opposition à l'oligarchie de Meiji à l'intérieur, protéger les intérêts du Japon sur le continent, en Corée et en Chine à l'extérieur. Cette double caractéristique a eu pour effet de développer les effectifs de l'Armée et de la Marine, en temps de paix comme en temps de guerre, et de poser en termes nouveaux la gestion de troupes de plus en plus nombreuses dont il convenait d'assurer la cohésion morale et la discipline, dans un contexte marqué par une diversification accrue des missions des forces armées, la modernisation des armements et des techniques militaires, mais aussi par l'évolution même de la société japonaise durant l'ère Meiji.

\section{Forger les instruments juridiques et psychologiques de contrôle de la discipline militaire}

La mise en place d'une armée moderne, les tâtonnements autour de la nature même de cette armée - de métier ou de conscription - ont eu un impact sur le contenu et le calendrier de mise en place des nouvelles institutions militaires. L'organisation de la discipline militaire, dans cette phase transitoire, révèle néanmoins des schémas et des préoccupations constantes qui seront pleinement intégrés dans les dispositifs pérennes institués au tournant des années 1880.

\section{La genèse du système d'organisation de la discipline militaire}

Au moment où le nouveau gouvernement se met en place après avoir abattu le système shôgunal en 1868, il ne dispose pas de troupes propres, mais s'appuie essentiellement sur des contingents féodaux issus des fiefs, à la loyauté parfois chancelante. Lors de la guerre civile de Boshin qui oppose entre 1868 et 1869 partisans et adversaires du shôgun déchu, le « quartier général en charge de la Pacification » émet, à l'égard des troupes impériales, une première série de réglementations visant à protéger les

1. Sur ce processus, Masaya Nakatsu, «Les missions militaires françaises au Japon entre 1867 et 1889 ", thèse de doctorat Asie orientale et sciences sociales de l'Université Sorbonne Paris-Cité (Paris-Diderot), 18 janvier 2018 ; Ernst P. Presseisen, Before Agression : Europeans Prepare the Japanese Army, Tucson: University of Arizona Press, 1965.

2. Sur l'avènement de la conscription, notre article, "L'instauration de la conscription et l'avènement de l'Etat-Nation au Japon. Autour de l'ordonnance du 10 janvier 1873 », Revue historique des armées, 2017, n²87, p. 109-117. 
biens et la sécurité des civils et des étrangers lors des opérations militaires, mais il s'agit d'une réglementation provisoire et partielle car le « quartier » en question » n'a pas de pouvoir direct de sanction disciplinaire sur les troupes féodales ${ }^{3}$. En septembre 1869, une ébauche de juridiction militaire est créée au sein du Ministère de la Guerre avec la mise en place d'un «Contrôle général aux armées », Kyûmonshi, qui débouchera sur la mise en place des tribunaux de l'Armée le 20 mai 1872 et de la Marine le 14 avril de la même année. Entre-temps, les infractions commises alors par les militaires continuent de relever du droit pénal général, les fiefs possèdent leurs propres règlements disciplinaires et le pouvoir de sanction du Ministère de la Guerre ne concerne que les hommes du rang ${ }^{4}$.

Cependant, le 26 mars 1872, est établie une première mouture de code pénal militaire, les "dispositions pénales concernant la Marine et l'Armée » kairikugun keiritsu $u^{5}$, en 204 articles. Ce document est important à plusieurs titres : d'abord, il restera en vigueur, après amendements divers, pendant près de dix ans jusqu'à la mise en place de codes spécialisés et s'appliquera en conséquence à l'armée de conscription. Ensuite, après l'abolition des fiefs, leur remplacement par des préfectures en août 1871 et la suppression des armées féodales, il constitue la première réglementation nationale sur la discipline militaire en temps de paix. Enfin, il entérine l'existence d'un statut pénal propre aux militaires. En 1872, est établie également la première génération des règlements internes des troupes, guntai naimusho, qui organisent, sur le modèle français et hollandais, la vie de caserne et les responsabilités respectives des chefs de corps, tandis que le Ministère de l'Armée, en octobre 1874, édicte les manuels d'instruction et d'entraînement militaires propres aux trois armes (infanterie, cavalerie, artillerie). Les «dispositions », sont accompagnées, le 6 février 1872, de l'adoption d'une sorte de bréviaire du soldat, dokuhon, en sept chapitres qui, sous ses versions révisées, restera en vigueur jusqu'en 1934, et sera intégré à son livret militaire. Ce bréviaire rappelle ainsi que la mission de soldat est de veiller au prestige de la Maison impériale et de protéger l'Etat dans un esprit de sincérité et de loyauté. A cet effet, il propose un catalogue de vertus morales que le soldat doit cultiver : la politesse, la fidélité, l'esprit de camaraderie, l'application au travail, le discernement, le courage, la dignité, la frugalité, le sens de l'honneur, le respect des lois, l'obéissance. Sur ce dernier point, on relève qu'il était néanmoins possible d'objecter à un ordre du supérieur. Ce bréviaire faisait l'objet d'une lecture solennelle au moment de l'incorporation sous les drapeaux et les nouvelles recrues faisaient serment par écrit de les respecter. Il comportait également toute une série de prohibitions jugées incompatibles avec la condition de soldat, assorties de sanctions pénales et disciplinaires dont la nomenclature révèle la nature des comportements délictueux observés sur le terrain, et qui constituent en grande partie l'antithèse des vertus précitées: complot, désertion, vol, jeu, vente forcée, négoce de prêt ou d'emprunt

3. Rikukaigun he no tasshigaki narabini rikugun shohatto, instructions relatives à l'Armée de terre et à la Marine et régulations de l'Armée de terre du 13 mars 1868, dans Watanabe Ikujirô-hen, Kiso shiryô kôgun kensetsu-shi (Documents fondamentaux, histoire de la création des armées impériales), Tôkyô, Kyôritsu shuppan, 1944, p. 37-39.

4. Naikaku kirokukyoku-hen, éd. direction des archives du Cabinet, Hôki bunrui taizen (Compendium classé des lois et règlements), vol.45, heisei-mon (1) (partie sur les institutions militaires 1), Tôkyô, Hara shobô, 1977, p. 262.

5. Kokuritsu kokkai toshokan, dijitaru korekushon, Bibliothèque Nationale de la Diète, collections numériques [désormais KKTDK], http://dl.ndl.go.jp/info:ndljp/pid/994769/1. Site consulté le 27 novembre 2017. 
d'argent, rixe, ivresse, luxure, escroquerie, négligence, lâcheté, violences et mauvais traitements contre les civils...Les crimes de complot, de désobéissance aux ordres, d'insulte à supérieur, de menaces et violences étaient les plus sévèrement réprimés.

Ce premier type de dispositif est mis en place avant l'adoption de la conscription, à une époque où les armées impériales sont encore majoritairement composées d'anciens samurai et les «dispositions » précitées en portent la trace : les officiers convaincus de crimes sont condamnés à la peine capitale par suicide, jisai, et l'on relève de nombreuses sanctions afflictives et disciplinaires qui touchent à l'honneur de l'officier (radiation, dégradation, confinement...), alors que le simple soldat est également passible de châtiments corporels comme les verges ou la bastonnade ${ }^{6}$. Néanmoins, ce bréviaire a survécu aux «dispositions », sans doute parce que le conscrit, plus encore qu'un ancien samurai, était davantage exposé aux risques ainsi dénoncés: d'après les statistiques officielles de l'Armée de terre, la "criminalité militaire » se développe avec la conscription : en 1874, 70 militaires et assimilés avaient fait l'objet de sanctions, 530 en 1875, 1651 en 1876, 1087 en 1877, 2522 en 1880, soit 6,0\% des effectifs de l'époque pour cette dernière année. Sur la période, $14 \%$ en moyenne d'entre eux sont d'origine samurai et cette proportion décroit au fil des années ${ }^{7}$. Sans doute, faut-il être prudent dans le décryptage de ces premières statistiques: elles traduisent peut-être aussi l'accroissement des capacités de l'appareil militaire d'alors à dépister et à traiter ce type d'infractions. Mais il existe, dès les premières années de Meiji, des facteurs objectifs de nature à fragiliser la discipline de ces forces armées en construction: l'absence de coïncidence entre les anciennes hiérarchies féodales et la nouvelle hiérarchie militaire ; un système de soldes désavantageux pour les hommes du rang et les sous-officiers; l'amalgame parfois difficile entre un encadrement dominé par d'anciens samurai et la masse des appelés ; un service militaire ressenti d'abord comme une contrainte, et dont la nécessité comme la signification échappent à la population ${ }^{8}$. Par ailleurs, la cohabitation entre les soldats - surtout ceux d'origine samurai - et la population laisse parfois à désirer : voies de fait, ivrognerie, débauche, tapages sur la voie publique, la multiplication des incivilités dégrade l'image de l'Armée auprès du public et compromet la légitimité même du service militaire ${ }^{9}$. Les instructeurs français, pour leur part, relèvent que soldats et officiers, surtout les citadins, sont rebelles à la discipline, inconstants et capricieux ${ }^{10}$.

Quoi qu'il en soit, il ne fait aucun doute que le gouvernement, tout à la préoccupation de créer une armée moderne, ne pouvait se désintéresser des manquements

6. Miura Yûji, Kindai nihon gunsei gaisetsu (Précis des institutions militaires du Japon moderne), Tôkyô, Shinzansha, 2013, p. 199-200 ; Naikaku kanpô kyoku, direction des publications officielles, Hôrei zensho, daiyonkan (Recueil des lois et règlements), vol.4, Tôkyô, Hara shobô, 1974, p. 874-875; Asakawa Michio, Meiji ishin to rikugun sôsetsu (La Restauration de Meiji et la création de l'Armée de terre), Tôkyô, 2013, Kinseisha, p. 242-244. ; Kumagai Teruhisa, Nihongun no seishin kyôiku (La formation psychologique des armées japonaises), Tôkyô, Kinseisha, 2012, p. 18.

7. Ibid., p. 80. La hausse des statistiques s'explique en partie par l'impact de la révolte de la Garde impériale de 1878 et la multiplication des heurts avec la police.

8. Yui Masaomi et al., Heitai heishi (Soldats et troupes), dans Nihon kindai shisô taikei, (Compendium de la pensée du Japon moderne), Tôkyô, Iwanami shoten, 1989, vol. 4, p. 474-478.

9. Sakamoto Yûshin, Kingendai nihon no gunji-shi (Histoire militaire du Japon moderne et contemporain), Tôkyô, Kaya shobô, 2012, p. 94-95, citant le témoignage d'un cadre militaire de l'époque, Tani Kanjô (1837-1911).

10. Meirion et Suzie Harris. Soldiers of the Sun. The Rise and Fall of the Imperial Japanese Army, New York, Random House, 1991, p.33. 
à la discipline militaire, surtout lorsque ces derniers prenaient une dimension collective : en décembre 1873 , le $11^{\text {ème }}$ bataillon de la préfecture militaire de Kumamoto se révolte et brûle sa caserne; l'année suivante, en décembre 1874, la caserne de la garnison de Kagoshima brûle à son tour à la suite d'un incendie à l'origine indéterminée, et l'ensemble de la garnison en profite pour déserter et retourner dans ses foyers. Les historiens s'interrogent encore aujourd'hui sur la cause de ces révoltes ponctuelles, mais ils observent que ces incidents, provoqués par des soldats d'origine samurai, ont pour cadre l'ancien fief de Satsuma, à un moment où, mis en minorité au gouvernement sur la question de l'opportunité d'une intervention militaire en Corée, Saigô Takamori (1828-1877), l'une des grandes figures de la Restauration, décide de se retirer sur ses terres de Satsuma.

Autre sujet de préoccupation : la multiplication des incidents, au début de l'ère Meiji, entre policiers et soldats, souvent pour des prétextes futiles. A l'origine, soldats et policiers étaient tous issus de l'ancienne classe des guerriers mais, à partir de l'introduction de la conscription en 1873, on assiste à des heurts entre policiers originaires de la classe des guerriers et des appelés issus de la conscription : incidents de Tôkyô de janvier 1874, de Shiba-atago no shitamachi, dans le sud de la capitale, en juin de la même année, d'Ueno en mars et avril 1875. La province n'est pas épargnée, puisque des échauffourées similaires éclatent à Ôsaka en janvier 1878, en février à Aomori, et à nouveau dans la capitale en septembre 1881, entre policiers et cadets de l'école militaire Kyôdôdan, occasionnant des tensions entre la préfecture de police de Tôkyô et le Ministère de l'Armée ${ }^{11}$.

Mais c'est la révolte des artilleurs de la Garde impériale en août 1878, motivée par la réduction générale des soldes opérée dans le cadre de l'austérité budgétaire décrétée à la suite de la Guerre civile du sud-ouest et le retard des récompenses pour la participation éminente de la Garde à la répression de la révolte des samurai de Satsuma, qui conduit les pouvoirs publics à sévir lourdement certes, sur le base des « dispositions » précitées. Car l'incident de Takebashi - le plus grave qu'aient connu les forces armées japonaises jusqu'à la tentative de coup d'Etat du 26 février 1936 - n'était pas une révolte de plus de samurai. Il touchait cette fois-ci un corps d'élite issu de la conscription.

Par ailleurs, la Guerre civile du sud-ouest de 1877 avait constitué le premier test de l'armée de conscription contre les partisans de Saigô Takamori qui étaient d'anciens samurai. Certes cette armée de «va-nu-pieds» avait tenu le choc du fait de son équipement supérieur, mais si les samurai de Satsuma avaient été largement surclassés sur le plan matériel, ils avaient fait preuve d'un fighting spirit supérieur qui leur avait permis de tenir six mois face à des forces plus nombreuses et disposant d'armements modernes. En outre, le gouvernement avait dû faire appel à des samurai loyalistes engagés comme «policiers », junsa, à la fois pour pallier les effectifs réduits de la conscription, mais aussi pour encadrer et stimuler l'ardeur au combat des appelés. Le gouvernement en avait conclu que si les samurai en tant classe sociale privilégiée étaient désormais obsolètes, voire discrédités, leurs valeurs martiales - ou du moins la

11. Sur ces points, Matsushita Yoshio, Nihon rikukaigun sôdô-shi (Histoire des troubles à l'intérieur de l'Armée et de la Marine japonaises), Tôkyô, Tsuchiya shoten, 1974, p. 63-67. 
représentation que les élites politiques s'en faisait - devait inspirer la formation morale du soldat ${ }^{12}$.

\section{La consolidation des années 1880}

La question disciplinaire est également indissociable du contexte politique de la première moitié de l'ère Meiji. En effet, à partir de 1874, l'oligarchie au pouvoir va être en butte à la montée en puissance du Mouvement pour la liberté et les droits du peuple, jiŷu minken undô, qui conteste le monopole du pouvoir par les grands clans du sud-ouest, en particulier Chôshû et Satsuma, réclame la mise en place d'un régime constitutionnel, la convocation d'une Assemblée élue, et critique la politique trop conciliante du gouvernement sur la question de la révision des traités inégaux conclus par l'Ancien régime dans les années 1850. Les autorités redoutent alors la capacité du Mouvement à fédérer les révoltes paysannes et de guerriers, à s'implanter dans les forces armées, et donc à faire de ces dernières un acteur politique autonome échappant au contrôle gouvernemental. Car la vie de caserne ménage à cette époque des plages de liberté, voire de laxisme, qui permettent aux militaires les plus éduqués d'avoir accès à la presse, de se documenter, de participer - illégalement - à des réunions publiques, d'organiser des cercles d'études, par où les idées du Mouvement pourraient pénétrer la troupe. A partir du milieu des années 1870, la protection de la «neutralité politique » des Armées, garante du principe d'obéissance et du respect de l'autorité hiérarchique, devint une préoccupation majeure des pouvoirs publics qui n'entendent pas que les militaires puissent mettre en cause la politique générale du gouvernement, et notamment les orientations de sa politique militaire, voire se laisser gagner par l'action directe.

L'incident de Takebashi avait été considéré comme une première alerte. Quelques années plus tard, en 1881, en pleine controverse autour de la vente à vil prix des actifs de la délégation au développement de Hokkaidô à des entrepreneurs proches de l'oligarchie, qui avait abouti, en octobre, à l'éviction du gouvernement de la faction d'Ôkuma Shigenobu (1838-1922), favorable au constitutionnalisme britannique, quatre généraux avaient pris l'initiative, au début septembre, de présenter une pétition à l'empereur contre cette vente et formulé des revendications politiques proches du Mouvement ${ }^{13}$. Le gouvernement avait alors adopté une série de mesures visant à rappeler les fondamentaux de l'éthique militaire d'une armée certes nationale, mais rattachée directement à l'empereur, tout en renforçant la réglementation sur la discipline militaire. Les «Avertissements aux soldats »de l'été 1878, du ministre de l'Armée Yamagata Aritomo (1838-1922) principalement dédiés au corps des officiers, et surtout l' "Admonition impériale aux soldats et marins » du 4 janvier 1882, à destination de l'ensemble des

12. Tobe Ryôichi, Gyakusetsu no guntai (Le paradoxe des forces armées), Tôkyô, Chûô kôron shinsha, 2012, p. 61. ; Ikuda Makoto, Nihon rikugun-shi (Histoire de l'Armée de terre japonaise), Tôkyô, Kyôikusha rekishi shinsho, 1980, p. 21-22.

13. Il s'agit de Torio Koyata (1847-1905), Tani Kanjô, Miura Gorô (1847-1926) et Soga Sukenori (1844-1935). Ces généraux, ne pouvant être incriminés dans le cadre de la législation pénale en vigueur, furent versés dans le cadre de réserve mais, attachés à une posture purement défensive de la politique militaire, n'en continuèrent pas moins à critiquer les velléités expansionnistes du haut commandement à travers leur association, Getsuyôkai, qui finit par être dissoute. Leur marginalisation coïncide par ailleurs avec la montée en puissance des germanophiles au sein de l'establishment militaire au détriment des francophiles dont ils étaient la figure de proue. 
troupes, participaient de cette réaffirmation solennelle de l'éthique militaire et érigeait l'obéissance en valeur absolue : «considérez les ordres de vos supérieurs comme émanant de Nous-même ». En conséquence, le droit d'objection préalable disparut des règlements militaires. L'édiction successive à la fin décembre 1881 des codes de l'Armée et de la Marine ${ }^{14}$ qui vont se substituer aux «dispositions » précitées, ainsi que des codes de justice militaire de l'Armée et de la Marine ${ }^{15}$ la création d'une police militaire - la Kenpeitai de sinistre mémoire - en mars 1881, la réorganisation des tribunaux militaires en septembre 1882, l'organisation du régime de sanctions disciplinaires en octobre $1911^{16}$, participent de ce renforcement de l'arsenal juridique propre à assurer une meilleure prise en considération de la «criminalité militaire » dans sa triple dimension : information, traitement et prévention. Cette législation définit les contours d'un statut militaire spécifique et dérogatoire du code pénal général dont le but est la «protection de la cohésion des forces armées et le maintien de la discipline ». Le fait que ce statut dérogatoire renferme de nombreuses dispositions passibles de la peine capitale est justifié par la nature même de la condition de soldat, « un univers privé des libertés communes dont jouit l'homme ordinaire, confronté éventuellement, dans sa mission, à la perspective de la mort », et par la nature même des infractions commises : il ne s'agit pas seulement de réprimer les atteintes à la morale individuelle et à l'ordre public mais de caractériser des crimes et délits d'Etat ${ }^{17}$.

On observe aussi que la neutralité politique des forces armées fait l'objet d'une attention particulière : la participation de militaires à des activités, réunions, libelles de caractère politique, la contestation, la critique, le dénigrement de la politique gouvernementale sont non seulement contraires aux obligations du soldat, mais punis pénalement (article 110 et 126 des codes de l'Armée et de la Marine). L'Admonition impériale aux soldats et marins, elle, devint rapidement « la charte sacrée et éternelle » du militaire ${ }^{18}$. D'abord parce qu'elle avait été promulguée sous l'autorité exclusive du souverain en l'absence de tout contreseing ministériel. Ensuite parce qu'elle était systématiquement lue dans les casernes lors des fêtes nationales et notamment des fêtes

14. Ordonnances du Ministère des Affaires Suprêmes n ${ }^{\circ} 69$ et 70 du 28 décembre 1881. Ces ordonnances ont été par la suite respectivement modifiées par le législateur en octobre et avril 1908. KKTDK, http://dl.ndl.go.jp/info:ndljp/pid/787961/77. Site consulté le 26 novembre 2017 ; ibid., http://dl.ndl.go.jp/info:ndljp/pid/797697/195?viewMode=. Site consulté le 26 novembre 2017.

15. Ordonnances du Ministère des Affaires Suprêmes n²4 et n8 des 4 août 1883 et 21 mars 1884. Ces ordonnances ont été par la suite respectivement modifiées par la loi en octobre 1888 et février 1889 , Japan Center for Asian Historical Records National Archives of Japan [désormais JACAR], référence $\mathrm{n}^{\circ}$ A15110495800, https://www.digital.archives.go.jp/das/image/M0000000000001705161. Site consulté le 26 novembre 2017 ; JACAR, référence $\quad \mathrm{n}^{\circ}$ A15110823400, https://www.digital.archives.go.jp/das/image/M0000000000001709153. Site consulté le 26 novembre 2017.

16. Ordonnance impériale militaire $\mathrm{n}^{\circ} 4 \mathrm{du} 13$ octobre 1911. Cette ordonnance fixe les sanctions infligées pour des manquements à la discipline et à l'honneur militaires qui ne constituent pas des infractions pénales (rétrogradation, mise aux arrêts simples, de rigueur etc...), JACAR, référence $\mathrm{n}^{\circ}$ A15113830500, https://www.digital.archives.go.jp/das/image/M0000000000001748186. Site consulté le 26 novembre 2017. Ce texte systématise des dispositions antérieures du même type.

17. Cette spécificité justifie par conséquent, selon Yamagata Aritomo, que ces codes soient plus sévères que le code pénal ordinaire: Tezuka Yukata, Meiji keihô-shi no kenkyû, jô (Recherches sur l'histoire du code pénal de Meiji), vol. 1, Tôkyô, Keiô tsûshin kabushiki kaisha, 1984, p. 269 sq.

18. Selon 1'expression du général Kuwaki Takaakira (1885-1945) dans son ouvrage paru en 1943 intitulé «50 ans d'histoire de l'armée de terre », Rikugun gojûnenshi, KKTDK, http://dl.ndl.go.jp/info:ndljp/pid/1460374. Site consulté le 7 décembre 2017. 
de l'Armée et de la Marine, expliquée par les chefs de corps au moins une fois par semaine. Enfin parce qu'elle suscita nombre de gloses et de commentaires édifiants, non seulement à destination des militaires, mais aussi du public.

\section{La discipline militaire à l'épreuve de la guerre}

Il va de soi que la discipline des armées, capitale en temps de paix, est cruciale en temps de guerre. L'épreuve du feu est l'occasion d'une vérification et d'une évaluation des dispositifs mis au point en temps de paix, dans des situations réelles de combat, où le comportement des troupes, leur moral, leur contrôle, participent de la victoire sur le terrain. Mais ces premières opérations militaires extérieures se déroulent aussi sous les yeux d'une "communauté internationale », attentive à l'évolution du rapport des forces en Asie Orientale en général, et qui scrute la capacité du Japon à intégrer le club restreint des nations dites «civilisées ». Trois moments de l'histoire du Japon ont été ainsi privilégiés : la guerre sino-japonaise, l'expédition des Boxers, la guerre russo-japonaise.

\section{La guerre sino-japonaise de 1894-1895 et la conquête de Taüwan}

La guerre sino-japonaise fut le premier conflit international d'envergure dans lequel le Japon a testé la capacité de ses forces armées sur le continent, contre une puissance certes déclinante, la Chine, mais qui disposait de forces terrestres bien supérieures en nombre, d'une très bonne marine et qui restait, pour l'archipel, une référence culturelle majeure, pour ne pas dire incontournable. Toutefois, le Japon, tant sur le plan du moral que des équipements et de l'entraînement militaires, lui était supérieur ; il avait rapidement acquis la maîtrise des mers et défait les troupes chinoises, dans la péninsule coréenne et en territoire chinois même. Officiellement, les autorités militaires ne pouvaient qu'être satisfaites de l'excellente tenue générale des troupes au combat. Car l'un des enjeux majeurs du conflit était de faire reconnaitre le Japon en tant que «nation civilisée », respectueux du droit international, et des lois de la guerre, contre une Chine arriérée et peu regardante sur la question ${ }^{19}$. Il est vrai que des consignes strictes avaient été données pour que la sécurité des biens et des personnes des Occidentaux, et notamment des missionnaires, soit garantie. Le général Ôyama Iwao (1842-1916), d'abord en tant que ministre de l'Armée, puis commandant de la $2^{\text {ème }}$ année, avait donné des instructions pour le Japon se conformât au droit international et traitât les civils, les prisonniers et les blessés avec humanité. A la fin juillet 1894, alors que la guerre n'avait pas encore été officiellement déclarée, la marine japonaise avait intercepté et coulé un transport de troupes chinoises portant pavillon britannique après les sommations d'usage. L'opinion publique britannique s'en était alors violemment prise au gouvernement

19. C'est bien le sens de l'ouvrage de Nagao Ariga, professeur à l'Ecole de guerre de Tôkyô, paru en français sous le titre, La guerre sino-japonaise au point de vue du droit international, Paris, Pédone, 1896, avec la préface de Paul Fauchille, alors directeur de la Revue générale de droit international public; Douglas Howland, "Japan's Civilized War: International Law as Diplomacy in the Sino-Japanese War (1894-1895) ", Journal of the History of International Law, 2007, vol. 9, n² ${ }^{\circ}$, p. 179-201. Ariga avait été conseiller juridique auprès de la $2^{\text {ème }}$ armée. 
japonais, mais il s'était avéré que la marine japonaise avait agi en conformité avec le droit international et la fièvre était retombée ${ }^{20}$.

Au total, à l'issue de la guerre, 1851 personnes avaient été déférées devant les tribunaux militaires, dont 370 seulement pour des infractions liées aux codes militaires, parmi lesquelles 318 pour désertion. C'est-à-dire que la majorité des auteurs d'infractions dont les tribunaux militaires ont eu à connaître avaient commis des crimes et délits de droit commun, notamment pour vol qualifié, ou «délits de mœurs », comme le jeu. Et surtout, $70 \%$ des prévenus traduits devant les tribunaux militaires étaient des supplétifs civils. Ce qui signifie que seuls environ 500 militaires - en majorité des sous-officiers et des hommes du rang - avaient été sanctionnés par ces tribunaux sur un effectif global de 174000 hommes mobilisés ${ }^{21}$. Est-ce à dire que les soldats japonais ont toujours eu un comportement exemplaire ? On peut légitimement en douter. D'abord parce que les tribunaux militaires n'ont été saisis que d'une fraction difficilement quantifiable de violations de la législation militaire : les réquisitions forcées de biens et de personnes en matière d'approvisionnement, de services, et surtout de transport, ont sans doute constitué un risque potentiel majeur pour les populations locales. Et puis, il y eut l'épisode du «massacre de Port-Arthur » en novembre 1894. Au moment de la chute du port, l'armée japonaise se serait livrée, à l'encontre des populations civiles, à des exactions qui auraient fait, selon les sources, contradictoires, entre 2000 et 60000 victimes, dénoncées par la presse internationale. Selon l'historiographie japonaise, ces violences auraient eu deux causes principales : 1) les soldats chinois en déroute auraient troqué leurs uniformes pour des vêtements civils et auraient harcelé les troupes japonaises; celles-ci dans l'impossibilité de distinguer combattants et non combattants, auraient exécuté systématiquement les civils «suspects »; 2) les Japonais auraient été excédés par les mutilations infligées aux cadavres de leurs camarades décapités, énucléés, châtrés, éviscérés, ou dont le nez avait été coupé. La vengeance aurait pu être ainsi un motif aux événements de Port-Arthur. Il convient aussi de rappeler que les autorités militaires japonaises ne s'étaient pas privées de mettre en garde la troupe contre la «barbarie chinoise » à l'encontre des prisonniers de guerre : Yamagata Aritomo, en septembre 1894 dans son ordre du jour aux officiers de la $1^{\text {ère }}$ armée, avait souligné qu'il valait mieux périr honorablement que de tomber entre les mains des Chinois. D'ailleurs, après la fin des hostilités, les Chinois n'avaient restitué que onze prisonniers de guerre dont dix supplétifs. Toujours est-il que cet incident avait embarrassé le gouvernement japonais qui, ne pouvant nier l'existence même de ces débordements, s'employa à les minimiser auprès des chancelleries, allant jusqu'à acheter la « bienveillance » de la presse étrangère. Aucun officier ni soldat ne fut inquiété pour le massacre de Port-Arthur; une enquête approfondie aurait pu conduire à la mise en cause du haut commandement et au remplacement des officiers généraux en charge de la direction des opérations militaires, sous le commandement unifié de Yamagata Aritomo - le grand rival d'Itô Hirobumi (1841-1909) au gouvernement - ce dont ce dernier ne voulait à aucun prix ; le

20. Du même auteur, "The Sinking of the S.S. Kowshing: International Law, Diplomacy, and the Sino-Japanese War", Modern Asian Studies, juillet 2008, vol. 42, n4, p. 673-703. Toutefois si les Japonais avaient porté secours aux membres occidentaux de l'équipage, les Chinois furent abandonnés à leur sort.

21. Pour le détail de ces références, Rikugunshô-hen, éd. Ministère de l'Armée, Nisshin sensô tôkeish (Recueil de statistiques concernant la guerre sino-japonaise), Meiji nijû shichi hachinen sen.eki tôkei kakan $2 / 2$ (Statistiques de la guerre des années 27 et 28 de Meiji [1894-1895]), vol.2/2, réédition Tôkyô, Kairo shoin, 2005, p. 794-802. 
gouvernement ne pouvait se permettre enfin de donner à l' incident une ampleur qui aurait pu entraver l'accession du Japon au club des « nations civilisées », et compromettre la révision des «traités inégaux » conclus à la fin des années 1850, fer de lance de la diplomatie meijiéenne depuis $1868^{22}$. L'affaire de Port-Arthur passa donc par pertes et profits.

Après la guerre, lorsque la Chine fut contrainte de céder Formose, l'Armée japonaise, lorsqu'elle se déploya dans l'île, se heurta aux activités de guérilla des aborigènes de l'île qualifiés de «brigands », dohi, auxquelles elle n'était pas préparée, avec son cortège funeste de raids-représailles qui servit de prétexte en juillet 1896 au massacre, à Yunlin, au centre de Formose, d'environ 6000 indigènes. Devant l'ampleur des réactions internationales, le spectre de Port-Arthur ne tarda pas à refaire surface. Le gouvernement fut contraint de démettre le responsable de la région, Matsumura Yûnoshin (1852-1921); les tribunaux militaires condamnèrent deux officiers - le commandant Satô Tsunemasa et le capitaine Ishizuka Ressaburô - à vingt ans de réclusion et des indemnités furent versées par l'empereur aux victimes ${ }^{23}$. Quoi qu'il en soit, après la victoire et la pacification de Taïwan, l'image de la Chine sortit considérablement dégradée, dans l'opinion publique, mais aussi dans les milieux militaires : pauvre, décadente, mal défendue, corrompue, «barbare », la Chine, de puissance culturellement tutélaire, devint une proie convoitée.

\section{L'affaire des Boxers en 1900}

Durant la guerre des Boxers de juin-août 1900, déclenchée par une société secrète chinoise anti-occidentale et anti-chrétienne avec le soutien du gouvernement chinois, un contingent international avait été mis sur pied pour porter secours aux légations internationales assiégées dans Pékin. Le contingent japonais en devint rapidement le plus important, avec 40\% des 33000 hommes déployés en août. Pour la première fois depuis la Restauration, le Japon participait militairement à une coalition militaire internationale dont il était même la colonne vertébrale. Le haut commandement fut donc particulièrement attentif à ce que les troupes japonaises eussent un comportement doublement exemplaire. Au feu tout d'abord, mais aussi en termes de discipline. Sur instruction du Premier ministre Yamagata Aritomo, des ordres furent donnés pour punir de la plus extrême sévérité, et sommairement, toute exaction, même vénielle, commise contre les civils chinois, sans doute pour éviter la réitération du massacre de Port-Arthur qui avait déjà terni la réputation des armées japonaises. Le colonel Akiyama Yohifuru (1859-1930), responsable de la logistique de la $5^{\text {ème }}$ division d'infanterie, n'avait autorisé que la prise de trophées de guerre (armes, drapeaux...). Ces dispositions cependant n'empêchèrent pas les troupes japonaises de se livrer à un « honorable pillage », graceful looting, de Pékin, selon les termes d'un correspondant britannique, à l'imitation des

22. Sur cet épisode, Jeffrey M. Dorwart, James Creelman, "The New York World and the Port Arthur Massacre" Journalism Quarterly, 1973, vol. 50, n4, p. 697-701; Daniel C.Kane, “Each of Us in His Own Way: Factors Behind Conflicting Accounts of the Massacre at Port Arthur", Journalism History, Spring 2005, vol. 31, n 1, p. 23-33; Ôtani Tadashi, «Ryojun gyakusetu jiken no ikkôsatsu » (Considérations sur le massacre de Port-Arthur), Senshû hôgaku ronshû, 1987, n²5, p. 215-296.

23. Kashiwagi Ichirô, « Nisshin sensôgo Taiwan ni okeru chian mondai. Unrin gyakusatsu wo chûshin ni » (L'ordre public à Taiwan après la guerre sino-japonaise. Autour du massacre de Yunlin), Hôsei shigaku, mars 1996, n $^{\circ} 48$, p. $120-140$. 
autres forces internationales qui participèrent, avec plus de brutalité encore, au sac de la capitale chinoise, au point que dans le district de Tongzhou, au sud-est de Pékin, les habitants avaient dû trouver refuge auprès du corps expéditionnaire japonais ${ }^{24}$.

De façon générale, la presse internationale avait loué le comportement et la discipline des troupes japonaises et le lieutenant-colonel Shiba Gorô (1860-1945), dont la contribution à la levée du siège des légations avait été décisive, fut félicité et décoré par les puissances occidentales ${ }^{25}$. Un épisode devait cependant ternir ce concert de louanges : le vol et le détournement organisés d'un lot de lingots d'or par les troupes japonaises à Pékin et à Tientsin - incident dit de Bateigin - d'une valeur de 8 millions de taels soit 12 millions de yen, une somme considérable à l'époque. Le scandale avait fini par transpirer à la Diète japonaise et dans la presse. Le général Nogi Maresuke (1849-1912), commandant de la $11^{\text {ème }}$ division d'infanterie, avait diligenté une enquête interne qui avait recommandé le renvoi des officiers responsables, et il avait demandé à être lui-même relevé de ses fonctions. La Kenpeitai, saisie de l'affaire en février 1901, centra ses investigations autour du commandant du $9^{\text {ème }}$ régiment d'infanterie, le général Manabe Akira (1851-1918), que le ministre de l'Armée Kodama Gentarô (1852-1906) suspendit de ses fonctions le 21 juin 1902, ce qui lui ferma l'accès au poste de ministre de l'Armée. Trois officiers subalternes firent office de fusibles et traduits devant les tribunaux militaires, mais le 8 mai 1902, une ordonnance de non-lieu fut rendue. L'argent pillé ne fut jamais restitué au gouvernement chinois, et la purge souhaitée par la presse dans les rangs de l'Armée n'eut pas lieu ${ }^{26}$.

La guerre russo-japonaise, " guerre modèle »?

La guerre russo-japonaise fut cependant l'épreuve de vérité pour l'Armée de Meiji car, pour la première fois, le Japon était confronté à une puissance européenne majeure, blanche de surcroît : la Russie. Par l'ampleur des effectifs engagés, les pertes importantes subies sur le front - plus de 80000 morts dont 73,6\% de tués au combat - son coût exorbitant, la longueur des combats, l'apparition sur le champ de bataille d'armes nouvelles telles que les mitrailleuses, l'usage intensif de l'artillerie, et notamment de l'artillerie de siège, l'importance de la logistique, la guerre russo-japonaise préfigure en grande partie les guerres modernes. Non seulement la victoire avait été coûteuse en hommes, en matériel et en argent, mais elle avait également révélé certaines faiblesses dans le moral et la discipline des troupes qu'il avait fallu parfois contraindre à charger, dans un cas au moins, à la pointe des baïonnettes. Nombreux ont été également les témoignages faisant état de sérieux doutes sur la capacité des sous-officiers à tenir leurs troupes, une fois les officiers hors de combat. C'était également la première fois que le Japon était confronté à la question du traitement de masse des prisonniers de guerre. Le Japon avait signé la convention de la Haye de 1899 sur le droit de la guerre et, naturellement, le comportement du Japon à l'égard des quelque 80000 prisonniers de

24. Shimanuki Shigetoshi, Senryaku. Nichiro sensô (jô) (La stratégie de la guerre russo-japonaise), Tôkyô, Hara shobô, 1980, vol.1, p.103.

25. Standard, 18 août 1900 ; London Times, 28 août 1900.

26. Ben Middleton, "Scandals of Empire: The Looting of North China and the Japanese Public Sphere", dans Robert A. Bickers, Rolf G. Tiedemann (dir.), The Boxers, China and the World, Rowman \& Littlefield Publishers, New York, 2007, p. 115 -132. 
guerre russes était attendu. Dans un souci de respectabilité internationale, le Japon s'attacha à les traiter décemment, au point que le comité international de la Croix Rouge félicita le gouvernement japonais après la fin des hostilités ${ }^{27}$. Le retour des quelque 2000 prisonniers de guerre japonais tombés entre les mains des Russes fut plus difficile. Ils furent systématiquement interrogés par les autorités militaires sur les circonstances de leur capture. L'opinion publique, travaillée par l'idéologie officielle qui considérait la reddition comme honteuse, ne leur réserva pas un accueil franchement enthousiaste...Les officiers qui s'étaient rendus au combat ne furent pas traduits devant les tribunaux militaires, mais firent l'objet de sévères sanctions disciplinaires et administratives. En revanche, les officiers pris par l'ennemi à la suite d'une mission de reconnaissance ou de renseignement furent décorés et promus en fonction de la qualité des informations qu'ils avaient pu transmettre et des circonstances de leur capture ${ }^{28}$.

La guerre russo-japonaise mérite-t-elle alors le qualificatif de guerre « propre »? Oui si l'on en croit l'activité des tribunaux militaires : 4374 hommes déférés dont 26 officiers, soit 2040 au titre des infractions militaires, dont 1544 désertions ( 1 officier). Les chiffres objectifs sont supérieurs à ceux observés lors de la guerre sino-japonaise, mais rapporté aux effectifs mobilisés présents sur le terrain, 940000 hommes, le taux de "criminalité militaire » lui est en réalité inférieur. Cela dit, on observe deux caractéristiques. La première est le poids important des désertions intervenues au Japon même, avant l'envoi sur le front, qui représente environ $90 \%$ des militaires inculpés pour ce chef et 14 militaires inculpés pour « fuite devant l'ennemi »-un motif d'inculpation qui n'avait pas été observé dix ans auparavant. La seconde est la hausse du nombre de soldats jugés pour « infractions contre supérieurs »: 111. De façon générale d'ailleurs, selon ces données, la «criminalité militaire » aurait été plus importante à l'intérieur du pays que sur le front. Plus que les chiffres, faibles au demeurant, ce sont les tendances qu'ils révèlent: la guerre, la longueur des batailles, l'âpreté des combats - le combattant russe était d'une autre trempe que le malheureux soldat chinois et mieux équipé - sèment le trouble chez les soldats en partance. La propagande iconographique insiste sur deux aspects : le Japon mène une guerre «civilisée »: la Croix-Rouge japonaise soigne et secourt indifféremment les soldats russes et japonais. Mais ce sont les soldats russes qui se rendent, à genoux, dans une posture suppliante. Les témoignages de soldats contribuent cependant à édulcorer cette vision idyllique d'une guerre « exemplaire » : en août 1905, dans l'île de Sakhaline, loin des correspondants de guerre japonais et étrangers, des officiers ordonnent de fusiller 60 prisonniers de guerre russes et leur capitaine parce qu'il

27. Sur le sort réservé aux prisonniers de guerre russes, Matsuwaki Noboru, Roshiahei horyo ga aruita Matsuyama. Nichiro sensôka kokusai kôryû (Matsuyama arpentée par les prisonniers de guerre russes. Les échanges internationaux pendant la guerre russo-japonaise), Ehime, Ehime shinbunsha, 2005. Matsuyama est l'une des villes japonaises abritant l'un des 29 camps de prisonniers au Japon. Egalement, Nagao Ariga, La Guerre Russo-Japonaise : Au point de vue Continental et le Droit International d'après les documents officiels du grand état-major Japonais, Paris, Pédone, 1908.

28. Hata Ikuhiko, Nihon no horyo (Les prisonniers de guerre du Japon), Tôkyô, Hara shobô, 1998, 2 vols, vol.1, p. 9-10. 
n'était pas possible de les évacuer, et en représailles de combats qui avaient durement éprouvé les forces japonaises ${ }^{29}$.

\section{Les suites de la guerre russo-japonaise et la réforme du manuel des troupes}

Après 1905, l'armée japonaise se trouve dans une situation délicate. Certes, elle est sortie victorieuse du conflit, et cette victoire venant dix ans après celle contre la Chine, l'Armée et la Marine jouissent d'un prestige inégalé qui conforte et légitime le service militaire auprès de la population. Pourtant la discipline militaire traverse une période de turbulences qui, sous prétexte de tirer les leçons du conflit, incite les autorités militaires à une reprise en main généralisée de la formation du soldat.

\section{Les symptômes de la crise de la discipline militaire à la fin de la période de Meiji}

La victoire du Japon sur la Russie encouragea-t-elle le relâchement de la discipline militaire ? Divers incidents alertèrent en tout cas les autorités militaires : en janvier 1908, des vétérans appartenant à la l6ème division d'infanterie de Kyôto ne supportant pas d'être invectivés comme de vulgaires nouvelles recrues, désertent après avoir frappé leur sous-officier instructeur. En mars de la même année, trente-sept soldats appartenant à la $1^{\text {ère }}$ division d'infanterie de Tôkyô, pour protester contre un entraînement éprouvant, désertent et tentent de joindre, en vain, la résidence privée de leur chef de bataillon pour se plaindre. Peu de temps après, à Ôsaka ce sont des éléments de la $16^{\text {ème }}$ division précitée qui fracturent la porte de la caserne pour aller boire à l'extérieur alors qu'ils avaient déjà été réprimandés par un sous-officier pour ébriété. On voit même une grève se déclencher au sein du $27^{\text {ème }}$ régiment d'infanterie d'Asakawa. Ces affaires, abondamment rapportées par la presse, choquèrent l'opinion, moins en raison des faits eux-mêmes, que du caractère collectif des actes d'indiscipline, et sont même évoquées à l'étranger ${ }^{30}$. Les débordements sont mis sur le compte des failles dans l'éducation promue par l'encadrement, mais aussi des «progrès de l'instruction et de l'élévation générale du niveau d'éducation du soldat de base qui rendait les troupes plus sensibles au respect des droits individuels ». On relève ainsi l'inadéquation de l'instruction prodiguée à l'évolution de la mentalité du soldat. Plus significatif encore : "pas un soldat ne bougera si l'on considère que le commandement d'une armée civilisée exige des règlements uniformes transformant les troupes en une main d'œuvre servile ».

Les autorités militaires, peu sensibles à ces critiques, avaient sous les yeux des statistiques préoccupantes : celles du nombre de soldats traduits devant les tribunaux militaires : 16700 soldats avaient comparu devant ces tribunaux jusqu'à la guerre, mais 2222 en 1906, 1993 en 1907, 2130 en 1908 soit 6345 soldats au total, ce qui représente près de $38 \%$ de l'ensemble des inculpés depuis la mise en place des tribunaux militaires, en seulement trois ans. Par type d'infractions militaires les plus nombreuses, on observe

29. Takahashi Noriyuki et al., Nihon gunji-shi (Histoire militaire du Japon), Tôkyô, Yoshikawa Kôbunkan, 2013, p. 332-333. Sur le détail des statistiques concernant les infractions militaires durant la guerre, Rikugunshô hensan (éd. Ministère de l'Armée), Nichiro sensô tôkeishû dai jûgokan, keibatsu, senryôchi gyôsei [...] (Recueil de statistiques relatives à la guerre russo-japonaise, vol. 15 : infractions, administration des zones occupées [...]), Tôkyô, Tôyô shorin, 1995, p. 64-72.

30. Ludovic Naudeau, Le Japon moderne. Son évolution, Paris, Flammarion, 1909, p. 288-290. 
606 cas de désertion en 1906, 541 en 1907, 530 en 1908 ; le complot (76 cas en 1906, 23 en 1907, 68 en 1908); crimes et délits commis contre un supérieur (16 cas en 1906, 22 en 1907, 36 en 1908). Sur le long terme, la désertion a toujours constitué le principal motif de sanction, mais la hausse des infractions de complot et de celles commises contre un supérieur hiérarchique est une caractéristique de la période postérieure à la guerre russo-japonaise. Ces statistiques ne concernent que les infractions passibles des tribunaux militaires et ne reflètent sans doute pas l'étendue réelle du phénomène : la désertion ne relève des tribunaux militaires qu'au bout de six jours. Or la majorité des déserteurs réintégrant la caserne ou étant repris dans ce délai, ils relevaient en conséquence des seules sanctions administratives. Il est indiscutable que cette situation est révélatrice des contradictions au sein de la société japonaise. A partir de 1908, les rapports militaires et ceux de la Kenpeitai font également état d'actes de violences, d'indiscipline, d'ébriété et d'incivilité commis par de jeunes officiers et, en janvier 1910, le Ministère de l'Armée rappelle solennellement l'encadrement au devoir d'exemplarité vis-à-vis des appelés ${ }^{31}$.

Acteur désormais reconnu - et craint - sur la scène internationale, ses positions consolidées en Asie orientale et en particulier sur le continent chinois et dans la péninsule coréenne, le Japon est en proie à un phénomène d'anomie lié à la disparition des objectif nationaux de puissance qui avaient jusque-là soudé la nation, à l'affaiblissement des solidarités traditionnelles en raison de la modernisation, de l'industrialisation et de l'urbanisation du pays, au développement subséquent de nouvelles idéologies telles que le libéralisme, l'individualisme, mais aussi l'anarcho-syndicalisme et le socialisme. Déjà l'édit impérial de Boshin du 13 octobre 1908 avait solennellement appelé à un sursaut national face au «délitement » du système de valeurs. Là aussi les rapports du Ministère de l'Armée de février 1908 font état de la diffusion de tracts anarchistes dans les casernes et de nombreux autres mettent en garde contre l'expansion du socialisme, y compris dans la Garde impériale ${ }^{32}$.

\section{La réforme des manuels d'instruction militaire}

Dès l'époque de Meiji, les forces armées japonaises n'échappent pas au constat dressé par Michel Foucault, selon lequel l'institution militaire est d'abord une société «disciplinaire », encadrée par une production normative spécifique caractérisée par l'omniprésence du règlement. Les manuels d'instruction militaire témoignent de l'évolution de cette production normative, dont la fonction est certes de maintenir une discipline et une cohésion militaires transcendant les mutations que traverse l'archipel en pleine modernisation, mais qui témoignent, aussi, d'une volonté progressive d'indigénisation de ces normes au départ hétérogènes.

C'est ainsi qu'intervint, en décembre 1908, une réforme globale du manuel interne des troupes, afin d'adapter la condition du soldat au nouvel état des techniques militaires,

31. Voir par exemple, Gunmu kyoku gunji ka, bureau des questions militaires, direction des affaires militaires, Dai 9 go gunjika shôkô bôkô ni kansuru ken (Rapport $\mathrm{n}^{\circ} 9 \mathrm{du}$ bureau des affaires militaires : affaires relatives aux actes de violence commises par des officiers, année 1910), JACAR, code de référence $\mathrm{n}^{\circ} \mathrm{C} 03022956300$, https://www.jacar.archives.go.jp/aj/meta/image_C03022956300? Site consulté le 10 février 2018.

32. Hoheika, bureau de l'infanterie, Shakaishugisha ni kansuru ken (Affaires concernant la présence de socialistes, année 1910), ibid., C03022983900, https://www.jacar.archives.go.jp/aj/meta/image_C03022983900? Site consulté le 20 février 2018. 
de la nature des combats, et des changements intervenus dans les armements et équipements militaires ${ }^{33}$. Cependant, au-delà de ces aspects techniques, c'est la philosophie d'ensemble de la réforme qui attire l'attention : il s'agit ainsi de renforcer le caractère normatif des manuels d'instruction militaire, alors que les chefs de corps disposaient jusque-là d'une certaine marge d'interprétation, et de mettre en perspective le statut du militaire par rapport à l'évolution globale de la société japonaise, pour en prévenir les effets dysfonctionnels potentiels sur le moral et la discipline militaires. Dans la foulée, furent ainsi successivement édictés, entre 1909 et 1912, les manuels de l'infanterie, de l'artillerie, du train et de la cavalerie. Pour la première fois, l'Armée, stimulée par sa victoire sur la Russie et par l'assurance que l'Empire faisait désormais partie des Grandes puissances, entendait se doter d'un corpus de règles nationales spécifiques et systématiques concernant la tactique militaire, l'entraînement, et la psychologie de ses forces qui ne soit pas seulement un démarquage des modèles français et allemand. Quant aux motivations de la réforme du manuel interne des troupes, elles se trouvent clairement expliquées dans l'exposé des motifs qui souligne en ces termes la situation délicate dans laquelle se trouvent les forces armées du pays :

\begin{abstract}
Au moment où le sens de la discipline guerrière s'éclipse peu à peu dans notre pays, mais que tarde à se mettre en place de nouvelles normes de culture et de civilisation, la société est en proie à une perte généralisée du sens moral, s'adonne à l'indolence et au lucre. On voit ainsi se développer des cessations concertées de travail, des violences sur les lieux de travail, autant de signes prémonitoires qui favorisent l'essor du socialisme et le désordre social. En ces temps de déclin de l'autorité publique, il devient difficile aux seules forces armées de maintenir la rigueur de la discipline militaire en se dressant à contre-courant de la sociétés ${ }^{34}$.
\end{abstract}

L'organe de la Kaikôsha - l'amicale des officiers de l'Armée de terre - dresse alors un portrait sans concession de la société japonaise minée, selon elle, par le culte de l'argent, le matérialisme, l'appât du gain, la multiplication des affaires de corruption, de détournement de fonds et d'escroquerie, la hausse des suicides et des meurtres, le déclinisme, l'injustice et l'hypocrisie. L'un des objectifs de la réforme du manuel interne des troupes est donc de prévenir les militaires de ces tendances pernicieuses, mais aussi de faire face aux contraintes liées à l'abaissement du service militaire à deux ans au lieu de trois, décrété en octobre 1907, non pour des raisons libérales, mais pour disposer de troupes plus nombreuses avec l'augmentation du nombre de divisions, tout en limitant le coût budgétaire et l'impact socio-économique défavorable d'un service militaire trop long $^{35}$. En somme, il s'agit de fabriquer, sur un temps plus court, un soldat dont la formation psychologique, seishin kyôiku, l'esprit d'offensive incarné par la charge à la baïonnette et le corps à corps, l'amour de la patrie et la loyauté envers le trône ne soient pas émolliés par l'évolution ambiante de la société, et lui permettent de faire face aux impératifs et contraintes de la guerre moderne qui modifient non seulement la physionomie et la durée des combats, mais aggravent aussi considérablement les pertes

33 . Ordonnance impériale militaire $\mathrm{n}^{\circ} 17$ du $1^{\text {er }}$ décembre 1908, KKTDK, http://dl.ndl.go.jp/info:ndljp/pid/904580/121. Site consulté le 4 décembre 2017.

34. Cité dans Rikugunshô-hen, Ministère de l'Armée éd., Rikugunshô enkaku-shi ji Meiji 37 nen shi Taishô 15 nen (Histoire du Ministère de l'Armée de 1897 à 1926), Tôkyô, Gannandô shoten, 1969, vol. 1, p. 166-167.

35. Le taux de conscription qui était stable à 5\%-6\% d'une classe d'âge, atteint 10\% en 1897 et double après la guerre russo-japonaise : Endô Y., Kindai Nihon guntai, op.cit., p.15. 
au feu. Très clairement, le nouveau manuel interne des troupes assigne à cette formation psychologique un objectif : remporter la victoire partout où, sur le terrain, l'armée japonaise serait éventuellement en état d'infériorité numérique ou matérielle. Le manuel de l'infanterie de 1909, hohei sôtei, et le «programme d'instruction aux fantassins » de 1911, hohei kyôtei, insistent sur la nécessité de bien traiter les prisonniers, mais excluent tout repli ou reddition: "pas un pouce de terrain pris sur l'ennemi ne doit lui être rendu »; "vous ne subirez pas le déshonneur et la honte de vous rendre à l'ennemi et de vous constituer prisonnier»; "plutôt mourir au combat tel un cristal aux éclats dispersés »: une métaphore d'un chant militaire célèbre de 1886, et qui résonne déjà singulièrement quand on connaît le comportement désespéré de certains unités, trente-quatre ans plus tard, sur les champs de bataille du Pacifique ${ }^{36}$.

Le second volet de la réforme est l'introduction de l'idéologie familialiste, là où les anciens manuels d'instruction se bornaient à un catalogue de règles techniques ou de maintien de l'ordre dans les casernes. Selon les nouvelles prescriptions du manuel interne des troupes, « la caserne est la famille du soldat, l'espace où tous partagent les joies et les peines de l'existence, où tous sont confrontés à la même expérience de la vie et de la mort ». Les sous-officiers instructeurs sont assimilés à un "père exigeant », leurs homologues en charge de l'intendance et des fournitures à une «mère attentive ». Plus généralement, «le supérieur doit traiter et protéger ses subordonnés comme s'ils étaient ses propres enfants »; « la caserne est le lieu d'apprentissage de la discipline militaire. Son objectif principal est l'inculcation d'une stricte discipline qui structure et organise la vie quotidienne du soldat. Toutefois, comme elle constitue aussi, avec les sous-officiers, une famille, il est important que, dans les limites de la discipline militaire, puisse s'y épanouir les goûts et plaisirs, ainsi que la concorde, propres au groupe familial». Il convient de remarquer cependant que l'introduction de l'idéologie familialiste n'est pas propre aux forces armées : la fin de l'époque de Meiji à partir de 1910, est caractérisée par la systématisation de l'idéologie de l'Etat-famille, kazoku kokka, dans le système éducatif en particulier, à travers les manuels d'histoire et d'éthique du primaire rédigés directement par le Ministère de l'Education à partir de 1903. Cette idéologie s'appuie sur la coïncidence entre piété filiale et loyauté à l'égard du souverain, dans laquelle l'Etat est le prolongement de la cellule familiale et les rapports entre l'empereur et ses sujets de même nature que ceux qui gouvernent les relations entre le chef de famille et ses enfants. Il n'est donc pas exagéré de soutenir que l'introduction de l'idéologie familialiste dans les casernes a anticipé le mouvement qui s'est développé dans le système éducatif. Faut-il voir dans la métaphore familiale la volonté de tempérer la rigueur de la discipline militaire ? Certes, l'obéissance des subordonnés ne pouvait être obtenue par la seule crainte de la punition ou de la sanction. Mais si elle participe de la mise en œuvre, dans le cadre militaire, de l'idéologie de l'Etat-famille, elle ne serait alors qu'une entreprise de rationalisation et d'intériorisation des mécanismes de domination caractéristiques du système impérial avant 1945. D'ailleurs, la métaphore familiale vient au contraire conforter le principe hiérarchique : si l'on en croit, les «nouvelles règles à observer par le fantassin », kaisei hohei suchi, de novembre 1905, "dans une famille, les enfants obéissent à leurs parents et la femme sert son mari ; si les enfants désobéissent à leurs

36. Takahashi N. et al., Nihon gunji-shi, op.cit., p. 340 ; Edward J. Drea, Japan's Imperial Army. Its Rise and Fall, 1853-1945, University Press of Kansas, 2009, p.134-135. 
parents et si la femme ne sert pas son mari, comment la famille pourrait-elle tenir ? ${ }^{37}$. On le voit, la référence à la famille, à l'existence d'une communauté de vie entre l'encadrement et la troupe ne construit pas une figure de l'officier qui se démarquerait du modèle d'autorité au profit d'un modèle aristocratique valorisant un rapport affectif et personnifié à la figure du chef $^{38}$.

Le troisième volet insiste sur la continuité entre éducation nationale et formation militaire. Le nouveau manuel interne des troupes met ainsi en valeur le service militaire en tant qu'instrument d'édification populaire :

Grâce à la formation reçue sous les drapeaux, le soldat sera non seulement initié à ses obligations fondamentales en tant que militaire, mais il sera aussi imprégné de ces éléments de morale nationale qui lui seront utiles tout au long de sa vie. De retour au pays, il pourra se consacrer à ses diverses activités en tant citoyen honnête et simple ; il sera un exemple pour ses compatriotes et affermira ainsi la direction que doit prendre la nation.

Dans cette optique, l'incorporation des élèves des écoles normales de formation des enseignants est jugée indispensable par la Kaikôsha : par la formation militaire que les futurs enseignants auront reçue, ils seront, plus tard, à même de transmettre à leur tour leur propre expérience à leurs élèves, le sens de la hiérarchie, de la connaissance du milieu militaire et de ses valeurs ${ }^{39}$. La continuité est ici double : d'une part entre la vie de caserne et le retour à la vie civile, d'autre part dans l'ensemble du processus éducatif : le rescrit impérial sur l'éducation de 1890, visait à distiller dans la jeunesse les vertus nationales censées exprimer la splendeur et l'exceptionnalité de l' «essence nationale » du Japon, le kokutai, concept totémique du Japon impérial, tandis que, parvenu à l'âge de la conscription, le jeune était initié au versant martial de cette essence nationale à travers l'Admonition impériale aux soldats et aux marins. Par cette continuité, l'école et la caserne conjuguaient ainsi leurs efforts pour former de «bons sujets », ryômin, et de « bons soldats », ryôhei, mais aussi, sans doute, pour détourner la jeunesse des «idées dangereuses » et subversives dont l'essor, à l'orée du $\mathrm{XX}^{\mathrm{e}}$ siècle, devint l'une des préoccupations majeures des élites politiques japonaises ${ }^{40}$.

Le quatrième volet développé par le nouveau manuel interne des troupes est l'agrarisme, dans laquelle on pourrait voir la version japonaise de la fameuse injonction de Philippe Pétain (1856-1951) en juin 1940 : «la terre ne ment pas ». En 1909 et 1910, le ministre de l'Armée réunit les chefs de bataillons et les responsables d'état-major : il faut encourager dans les casernes l'horticulture et les travaux agricoles, non pour des

37. KKTDK, http://dl.ndl.go.jp/info:ndljp/pid/844468/145. Site consulté le 4 décembre 2017. Ce document fait partie des manuels militaires publiés par l'Armée à destination du grand public et des administrations ; ils se distinguent des manuels d'instruction à usage interne. On y trouve les principes fondamentaux qui doivent inspirer la vie et le comportement du soldat, mais aussi des modèles de correspondance ou de discours (départ ou retour du front, condoléances etc...) : Ichinose Toshiya, Meiji, Taishô, Shôwa guntai manyueru. Hito wa naze senjô he itta no ka (Les manuels militaires des époques Meiji, Taishô et Shôwa. Pourquoi les hommes vont-ils à la guerre ?), Tôkyô, Kôbunsha, 2004.

38. Sur cette distinction, Jean Boulègue, « De l'ordre militaire aux forces républicaines : deux siècles d'intégration dans la société française », dans André Thiéblemont (dir.), Cultures et logiques militaires, Paris, PUF, 1999, p. 261-288.

39. Kaikôsha kiji , août 1911, n430, p. 19.

40. Sur la contribution de l'éducation à la formation de l'esprit martial, Hatano Harufusa, Shôgakkô ni okeru gunjin seishin no kosui (L'inculcation de l'esprit militaire à l'école primaire), Tôkyô, Shôbunsha, 1912. 
motifs d'autosuffisance ou esthétiques, mais idéologiques: les soldats doivent être pénétrés de la beauté et de la simplicité de la nature, mais aussi de la compétition et de la lutte pour la vie qu'elle induit. Ils acquerront par ce biais des compétences et des sensibilités qu'ils pourront aussi mobiliser quand les appelés réintégreront leurs campagnes, loin de la corruption et de l'univers cosmopolite des villes ${ }^{41}$. Transparaissent dans cette initiative une méfiance à l'égard de la culture urbaine et une nostalgie pour les vieilles hiérarchies et solidarités communautaires liées au travail agricole, à une époque où les évolutions de la société japonaise et des profils sociologiques des conscrits signent le déclin, lent mais inexorable, des masses paysannes et l'essor des grandes métropoles. Cette méfiance justifie aussi que la caserne soit plus isolée de la société civile. Alors que la sortie était de rigueur les jours de congés, les nouveaux manuels d'instruction requièrent que les soldats prennent leurs congés sur place, dans les cantonnements, pour éviter, selon la Kaikôsha, «la contamination des militaires par les lumières de la ville ». Dans la même veine, la possibilité pour les militaires de détenir dans les casernes des livres et des revues, ou d'y avoir accès fut limitée et, dès décembre 1905, une instruction du Ministère de l'Armée exigea de soumettre à l'autorisation préalable de la hiérarchie tout projet de publication ou d'articles, y compris, le cas échéant, ceux à prétention scientifique ou académique ${ }^{42}$. Cette valorisation des travaux agricoles en tant qu'idéal-type $\mathrm{du}$ «bon soldat », fut un échec, mais l'agrarisme contribuera de prospérer malgré tout dans toute une frange du nationalisme japonais, au lendemain de la dépression économique provoquée par le krach de Wall Street d'octobre 1929, notamment auprès des jeunes officiers ulcérés par la dégradation subséquente de la condition paysanne.

\section{La question lancinante des mauvais traitements et autres châtiments corporels}

L'Admonition impériale aux soldats et aux marins appelait certes au respect du principe hiérarchique, mais intimait aussi aux «supérieurs de s'abstenir de tout comportement méprisant ou arrogant à l'encontre de leurs subordonnés ». Et d'ajouter : «s'il arrive qu'ils doivent faire preuve d'autorité dans l'accomplissement des fonctions, ils auront à cœur de les traiter avec affection». La rupture de cette «harmonie », distillant «le poison au sein des forces armées » dont les responsables «passeront pour des criminels impardonnables aux yeux de l'Etat». On peut donc déduire de cette rhétorique que la rigueur du principe hiérarchique n'autorise pas des rapports de violence réciproques, de toute nature, entre supérieurs et subordonnés. A noter que le projet de code pénal de l'Armée de 1881 prévoyait, dans son article 97, que les «militaires ne peuvent frapper ou injurier leurs subordonnés sous peine d'un emprisonnement allant de deux mois à trois ans ». Mais, cet article n'avait pas été retenu dans la version définitive $\mathrm{du}$ code. Juridiquement, seuls les officiers disposaient du droit de punition, mais les manuels internes des troupes restaient flous sur les fondements et les conditions

41. Kaikôsha kiji n413, juin 1910, p. 1-7.

42. JACAR, https://www.jacar.archives.go.jp/aj/meta/image C08070693100. Site consulté le 26 novembre 2017. 
d'exercice de ce droit ; la frontière entre la punition légitime et la violence illégale ${ }^{43}$ devint rapidement poreuse; l'éducation et la discipline des troupes relevaient de la prérogative d'indépendance du commandement suprême des armées, et ni le gouvernement ni, a fortiori, la Diète, n'avaient qualité pour intervenir dans ce domaine et prévenir les abus d'autorité ; la qualité des sous-officiers était médiocre : carrière et traitements peu attractifs, faibles chances de promotion, mais responsabilités accrues en matière de formation dans le cadre des nouveaux manuels d'instruction. La combinaison de ces différents facteurs favorisa, dans les casernes, le développement des « sanctions privées », shiteki seisai, c'est-à-dire des punitions, brimades, vexations, humiliations, châtiments infligés par la hiérarchie sur les subordonnés, mais aussi par les anciens sur les plus jeunes. Ces sanctions privées, individuelles et collectives, sont motivées par une faute dans l'accomplissement du service (retard à l'appel, tenue négligée ou non réglementaire, mauvais entretien des équipements, manque de respect...). Elles prennent des formes diverses et sophistiquées - la gifle, les coups et l'insulte en sont les formes les plus banales - jusqu'au racket ou aux corvées imposées par les anciens sur les hommes du rang. Le discours familialiste autorise et justifie le droit de punition du supérieur. Selon les «nouvelles règles à observer par le fantassin », kaisei hohei suchi, publiées en novembre 1908, « le supérieur doit se comporter vis-à-vis du soldat de la même façon qu'un parent (père et mère). La punition ou la réprimande ne doivent pas être un objet de ressentiment à l'égard du supérieur...Ce n'est pas par haine que le supérieur doit punir, mais pour éviter la réitération d'une faute ou redresser un mauvais comportement. Même si l'on considère que la punition est injuste, il faut aussitôt s'y conformer, sans discussion $»^{44}$.

Quant aux châtiments corporels, les forces armées japonaises n'en avaient pas le monopole : la Marine britannique par exemple s'était longtemps rendue célèbre par son système codifié de punitions sur ses bâtiments dont les espaces confinés et la promiscuité, mais aussi la manœuvre, exigeaient une discipline de fer, et qui inspirera d'ailleurs la Marine japonaise. La question est en tout cas délicate, car il n'existe aucune statistique officielle sur les châtiments corporels relevant de la catégorie des sanctions privées. Elle est documentée essentiellement par des témoignages de conscrits, victimes ou témoins de ces punitions, ou des journaux intimes tenus par les soldats. Même si ces témoignages sont récurrents, le problème de savoir si la caserne est, systématiquement, un foyer de violence reste discutée. Il est certain en revanche que ces cas de violence apparaissent très tôt. Avant même l'avènement d'un service national en 1873, dès les premières expériences de réquisition militaire en 1871, on observe de la part des sous-officiers instructeurs, issus pour la plupart de l'ancienne classe des guerriers, l'usage de «sanctions informelles » à l'égard des hommes du rang. Faut-il y voir un préjugé de classe ? Il est certain que le service militaire fait initialement cohabiter dans les casernes deux types de population qui restent marqués par les stéréotypes hiérarchiques traditionnels : d'anciens samurai qui appartenaient à l'élite politico-administrative de l'Ancien régime et des conscrits issus, en grande partie, d'une masse paysanne peu

43. Selon l'article 71 du code de 1908, les auteurs d'actes de mauvais traitements par abus de pouvoir s'exposent à une peine de travaux forcés ou d'emprisonnement inférieure à trois ans. Tout est évidemment affaire d'interprétation...

44. KKTDK, http://dl.ndl.go.jp/info:ndljp/pid/844311. Site consulté le 8 décembre 2017. 
éduquée $^{45}$. Les mauvais traitements apparaissent, déjà, comme la cause principale d'évasion et de désertion qui, localement, peut atteindre jusqu'à $50 \%$ des effectifs dépêchés par les fiefs ${ }^{46}$.

Il faut cependant attendre les lendemains de la guerre sino-japonaise pour que la presse japonaise s'en saisisse et, selon les spécialistes, c'est à partir de la guerre russo-japonaise que la routine des sanctions privées s'installe dans les casernes ${ }^{47}$. Une enquête menée par un médecin militaire en 1910 pour les années 1900-1907 (sauf pour les années de guerre 1904-1905) fait apparaître un taux de suicide moyen dans les troupes, de 0,62/1000, sensiblement supérieur à celui observé dans les armées étrangères comparables (ce taux était de 0,29-0,48/1000 en Allemagne, de 0,15-0,20/1000 en France, de 0,04 à 0,20/10009 en Hollande et de 0,12-0,14/1000 en Russie), mais inférieur à celui de l'Autriche. En 1910, par exemple, l'Armée recense 111 suicides dont 86 soldats de $1^{\text {ère }}$ et de seconde classe et 73 «bleus »: ce sont les soldats nouvellement incorporés qui en sont les principales victimes ${ }^{48}$. A l'époque, le Ministère de l'Armée peine à identifier les causes de ces suicides qu'il met sur le compte de la dépression ou de l'instabilité mentale. Mais pour les historiens, c'est la persistance, voire l'aggravation de ces «sanctions privées », qui l'explique : une tendance favorisée par l'existence des chambrées militaires, naimuhan, qui forment l'unité de base dans les casernes, composée de vingt à trente hommes sous la responsabilité d'un sous-officier instructeur, et qui structurent, encadrent et organisent aussi bien la vie quotidienne que l'entraînement des soldats ${ }^{49}$. Les autorités militaires en sont parfaitement conscientes : le général Nagaoka Gaishi (1858-1933), directeur des Affaires militaires au Ministère de l'Armée, attribue à ces débordements le nombre élevé d'otites et de perforations de tympans parmi les causes sanitaires de réforme, mais il en rend responsable les mauvaises manières des soldats plus âgés sur leurs cadets, et indique que les faits ayant lieu le plus souvent après l'extinction des feux, la hiérarchie a du mal à en prendre la mesure ${ }^{50}$. Le général Tanaka Giichi (1864-1929), futur chef du gouvernement, admet que la population a peur de l'Armée et du service militaire, mais qu'il importe de dissiper les «malentendus », car « la conscription ne saurait plus être synonyme d'oppression » $(\mathrm{sic})^{51}$. Toutefois, les pronostics de Nagaoka selon lesquels, grâce aux nouvelles directives, « les autorités centrales, éprises de chiffres, ne pourront que se réjouir de l'évolution des statistiques sur la désertion, les suicides par pendaison et le nombre de punis », seront cruellement, et rapidement, démentis par les faits. Le 26 août 1911, une instruction du ministre de l'Armée Terauchi Masatake (1852-1919) mettait à nouveau en garde les officiers contre les mauvais traitements à l'égard de leurs subordonnés dus à l'emportement et à une mauvaise appréciation du

45. Le taux d'analphabétisme et d'illettrisme atteint encore $60 \%$ des conscrits en 1891 , et $14 \%$ seulement d'entre eux sont passés par l'école primaire : E. J. Drea, Japan's Imperial Army, op. cit., p. 73.

46. Asakawa Michio, «Shinbi chôhei ni kansuru hitotsu kenkyû » (Recherches sur l'acte de conscription de l'an Shinbi [1871]), Gunji shigaku, juin 1996, vol. 32, n¹, p. 30 sq.

47. Jiji shimpô, 21 mars 1897 ; Ôhama Tetsuya, Tennô no guntai (Les forces armées de l'empereur), Tôkyô, Kôdansha, 2015, p. 88-89.

48. Shiromaru Fumio et Endô Yoshinobu, « Guntai kyôiku to kokumin kyôiku II, Guntai naimusho no kenkyû » (Education militaire et éducation nationale. Recherches sur les manuels d'instruction militaire II), Chiba daigaku kyôikubu kenkyû kiyô, décembre 1975, vol. 24 partie 1, p. 85.

49. Ibid. Ôhama T., Tennô no guntai, op.cit., p. 88 sq.

50. Kaikôsha kiji, mars 1910, n408, p.11.

51. Ibid., p. 13. 
principe de sévérité qui «entretiennent des rumeurs fâcheuses » dans l'opinion » alors qu'ils doivent au contraire "susciter l'adhésion de leurs subordonnés, contrairement à ce que l'on peut observer dans certains pays étrangers $»^{52}$. Ce document montre qu'à la fin de l'époque de Meiji, la hiérarchie prend conscience à la fois de la reproduction de la violence à tous les échelons de la chaîne de commandement, et des effets dysfonctionnels potentiels qu'elle induit, tant dans l'opinion qu'au niveau de la cohésion des troupes. Sans doute faut-il y voir aussi la volonté de faire en sorte que ces dysfonctionnements ne soient pas récupérés par les tenants des « idées dangereuses » ou n'alimentent les comportements anti-militaristes ou de fuite du service militaire dans la population ${ }^{53}$. En réalité, ces sanctions privées ne seront jamais éradiquées parce qu'elles participent d'une entreprise d'acquisition des automatismes d'obéissance et de nivellement des conditions tous les conscrits sont censés être logés à la même enseigne -, d'endurance, et qu'elles font partie intégrante des rituels et pratiques qui bornent la frontière symbolique entre la société civile et la caserne ${ }^{54}$.

Le maintien de la discipline militaire fut indissociable du processus de création d'une armée moderne, puis de diversification des missions qui lui étaient assignées. L'Armée de terre, force d'appoint de maintien de l'ordre et de la sécurité intérieure de l'Etat, dans un contexte marqué par la multiplication des révoltes et des oppositions armées, fut à la pointe du mouvement liant discipline militaire et formation psychologique. La prise de conscience de la Marine, davantage accaparée par la formation technique des marins, fut plus tardive, associée au tournant des années 1880, lorsque les forces armées entament une mue décisive, tournées vers la conquête d'un «espace vital» en Asie Orientale. Dans le même temps, l'accroissement des effectifs mobilisables, en temps de paix comme en temps de guerre, avec les réformes successives de la conscription, le nouveau visage même de la guerre, grosse consommatrice de ressources nationales et en hommes, posent en termes nouveaux la question du moral et de la discipline, tant individuelle que collective, des troupes. Cette discipline, qui s'appuie sur l'obéissance absolue aux ordres, se nourrit d'une dimension juridique, avec les codes et réglementations spécialisés, éthique avec les grands textes censés forger la psychologie du soldat, administrative avec les règlements de service qui organisent minutieusement le quotidien du soldat dans les casernes. Elle ne vise pas seulement à maintenir la cohésion interne des troupes, leur capacité de mobilisation et de réaction face aux situations critiques de combat, elle est également investie d'une dimension idéologique formatant la psychologie du «soldat de l'empereur », dont le drapeau et le fusil sont considérés comme le prolongement même de la personne du monarque. Cette dimension particulière est constamment mise en avant dans la formation psychologique et morale du soldat, car elle explique selon l'état-major, la victoire chèrement acquise sur la Russie. Elle doit donc être cultivée à tout prix pour faire la différence sur le champ de

52. Bureau des questions militaires, Rikugun kun jûgo go, kashi heisotsu kyôiku shidô jô chûisubeki ken (Instruction $\mathrm{n}^{\circ} 15$ concernant les points importants relatifs à la formation et à la direction des sous-officiers et soldats), JACAR, www.jacar.archives.go.jp/aj/meta/image C03023003100? code de référence C03023003100. Site consulté le 21 février 2018.

53. Kumagai T., Nihongun no seishin kyôiku, op., cit., p. 268.

54. Ôe Shinobu, Chôhei-sei (Le système de la conscription) [1981], Tôkyô, Iwanami shinsho, 2013, p. 110-112 ; Ôhama T., Tennô no guntai, op.cit., p. 93-95. 
bataille. Il reste que si la succession des dispositifs et régulations organisant la discipline militaire peut s'expliquer par les mutations de l'Armée et de la société japonaises durant l'ère Meiji, le renouvellement des cadres et des effectifs, cette récurrence laisse aussi entendre qu'elle n'était pas toujours aussi affermie. L'obéissance absolue aux ordres, le caractère spartiate de la vie de caserne, la dureté des entraînements avaient certes pour but d'endurcir le soldat, de transformer un paysan placide en une redoutable et redoutée machine de guerre. Mais elle s'avérera impuissante, bien au contraire, à endiguer, dans une partie du corps des officiers, le risque de subversion de la hiérarchie, comme le montrera l'histoire des années 1930. Surtout, la préséance accordée au mental et à l'esprit du soldat, outre qu'elle dissimule une philosophie et des méthodes coercitives qui pèsent lourdement sur le conscrit, amènera souvent l'état-major à sous-estimer le rôle des innovations technologiques militaires dans la conduite des guerres modernes et à brider les capacités d'initiative individuelle sur le terrain. Enfin, le discours autour des guerres « civilisées » menées par le Japon de Meiji sera plus tard instrumentalisé par les courants révisionnistes pour relativiser, voire nier, les exactions commises à grande échelle en Chine et pendant la guerre du Pacifique.

UNIVERSITE SORBONNE PARIS-CITE

CENTRE de ReCherche SUR LES CIVILISATIONS DE L'Asie ORIENTALE (CRCAO)

\section{Notice biographique}

Eric Seizelet est professeur émérite à l'Université Paris-Diderot, ancien pensionnaire de la Maison franco-japonaise de Tôkyô. Titulaire d'un doctorat d'Etat en droit et diplômé de l'Institut National des Langues et Civilisations Orientales, il est spécialiste de l'histoire du droit et des institutions politiques du Japon moderne et contemporain. Il est l'auteur, en autres, de Monarchie et démocratie dans le Japon d'après-guerre (Maisonneuve et Larose, 1990), Justice et magistrature au Japon (PUF, 2002) et, avec Régine Serra, de Le Pacifisme à l'épreuve, Le Japon et son armée (Les Belles-Lettres, 2009). 